\title{
Evaluation of environmental risk of manufacturing complexes
}

\author{
Tatyana Boiko $^{1}$, Iryna Dzhygyrey ${ }^{2}$, Alla Abramova ${ }^{3}$
}

1. Department of Cybernetics of Chemical Technology Processes, Natonal Technical University of Ukraine "Igor Sikorsky Kyiv Polytechnic Institute”, UKRAINE, Kyiv, Peremogy av. 37, E-mail: tvbojko@gmail.com

2. Department of Cybernetics of Chemical Technology Processes, Natonal Technical University of Ukraine "Igor Sikorsky Kyiv Polytechnic Institute”, UKRAINE, Kyiv, Peremogy av. 37, E-mail: dzhygyrey@gmail.com

3. Department of Cybernetics of Chemical Technology Processes, Natonal Technical University of Ukraine "Igor Sikorsky Kyiv Polytechnic Institute”, UKRAINE, Kyiv, Peremogy av. 37, E-mail: alla_abramova@ukr.net

Abstract - The article presents the implementation of the developed methodology for assessment of environmental safety level and identifying the environmental risk of industrial enterprises at life cycle stages. The proposed approach to environmental safety assessment can be applied not only to existing industrial enterprises but also at the design stage.

Keywords - assessment, damage, environmental management system, environmental safety, hazard, index, indicator, industrial object, risk.

\section{Introduction}

The current trend in the world to assess the impact of environmental factors on human health and environmental impact assessment is the application of risk assessment methodology. This kind of analysis is the most acceptable in managerial decisions, since it allows: to compare the risks of different nature and to identify the most important; to characterize quantitatively the potential and actual damage to human health; determine the priority of existing threats; to formulate an effective strategy and regulation tactics of technological regimes of industrial complexes. It is necessary to recognize that implementation of the risk assessment methodology in the management decision-making practice is constrained, in particular, by the absence of appropriate normative documentation in Ukraine. And there are also rare systematic computer databases that are needed for risk assessment.

Today, the risk is understood as a measure of hazard, but as a hazard distinguish phenomena, processes, actions, or conditions that are characterized by the presence of a potential that can harm human health, lead to death, damage natural environment, lead to loss of anthropogenic material objects. It is necessary to emphasize the probabilistic nature of this concept. There is no single way to measure or quantify risk. Here one should proceed from the available information and resources.

Built on the basis of these requirements, the environmental management system contains all the elements that are essential for a rational attitude to resources in production complexes.

The third edition of the ISO 14001:2015 standard, "Environmental management systems Requirements with guidance for use" is relevant in world practice in environmental management. The main advantage of the standard is the system approach and the balanced combination of processes that make up the well-known Deming cycle (PDCA, Pan-Do-Check-Act cycle).

\section{Methodology for assessing the environmental safety level of industrial enterprises}

When using the risk assessment methodology, it's always important to remember that we are dealing with estimates. In order to properly use these assessments for the development of technical and managerial decisions, for relations with public and administrative bodies, it is very important that the potential degree of uncertainty of these assessments is known. When 
developing a method for a comprehensive assessment of environmental hazard, it is possible to use different techniques, but one must ascertain whether determined results are unambiguous.

Taking into account the above-mentioned features, it is possible to develop a methodology for assessing the level of environmental safety of industrial enterprises, which can be summarized in the following stages. At the first stage, a system of indices is developed which determines quantitative indicators of industrial ecosystem component's quality or industrial object's state.

Here index is a measure of deviation from baseline (either from a standard, or from a steady state). In this context, the indices that have an absolute value must be given as relative values. In the second stage, the system of indexes is converted to a unified form using the desirability function. In the third stage, an assessment of the environmental (technogenic) risk is determined using dependencies of the "index-risk" method. The number of estimated indices can be very high in the quantitative risk analysis of industrial productions. The presentation of risk reduces this large amount of information, leading it to a managed form. At the fourth stage, the interpretation of the results is carried out [1].

This framework helps implementing the developed methodology for evaluating the level of environmental safety and identifying the environmental risk of industrial enterprises at all stages of life cycle, in particular, in the following techniques and assessment systems:

- methodology for assessment of environmental safety level and impact of industrial objects on the environment at the design stage;

- methodology for assessment of technogenic safety level and the impact of industrial objects on the environment;

- economic, ecological, and social sustainability assessment system of territorial units and industrial objects;

- methodology for assessment of environmental safety level and impact of industrial objects on the environment at the exploitation stage.

Let's consider the basic principles of the mentioned methods. Life cycle stage of production is fundamental in systems of indicators. The conceptual model of the environmental safety of industrial objects in designing is presented in Fig. 1 [2].

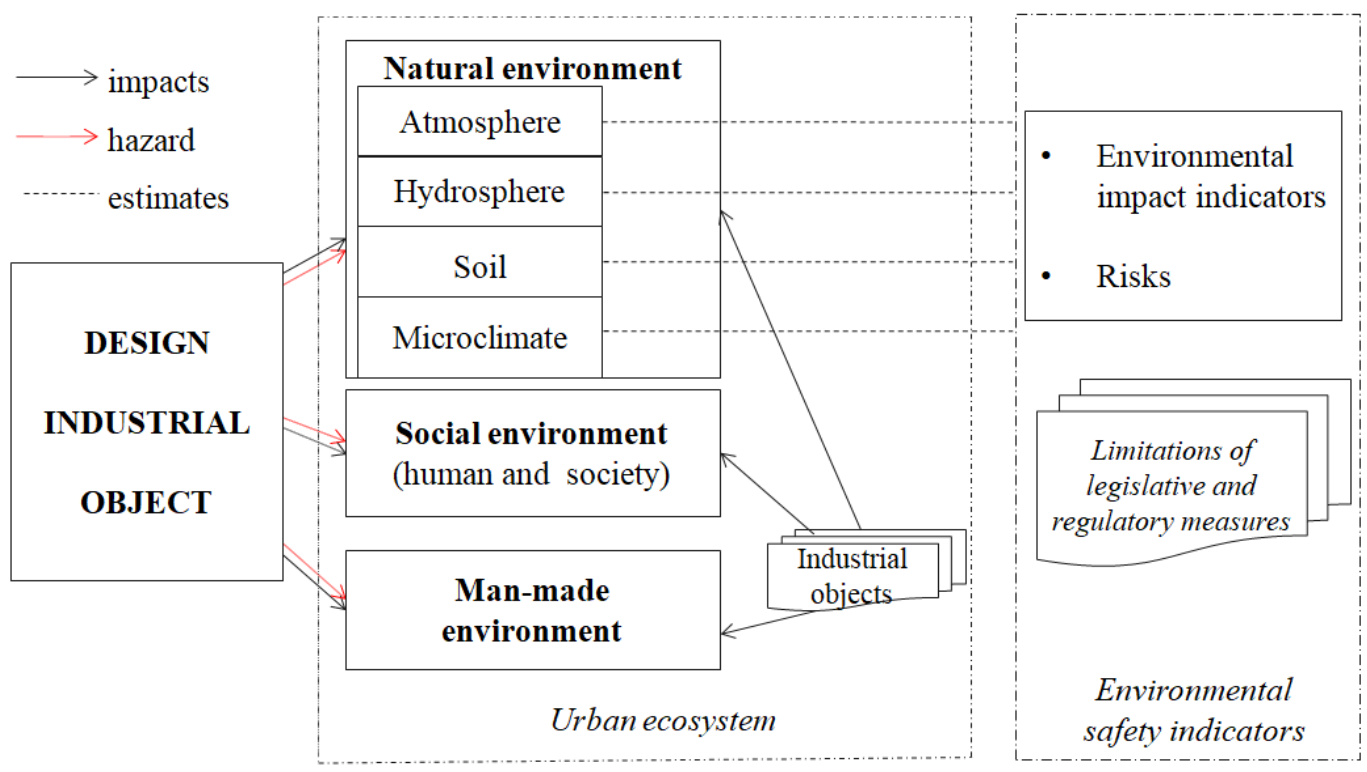

Fig.1. A conceptual model of the environmental safety assessment of a design industrial object. 
Considering ecological safety as a complex system it is possible to propose as ecological safety indicators of designed industrial object - risk indicator and environmental impact indicators of an industrial object which is implemented as a model of risk assessment using the indicators unification method:

$$
R_{E}=\sum_{i=1}^{m} r_{i}, \quad r_{i}=a_{i} \cdot e^{b_{i} \cdot I_{i}}, \quad r_{i, k}=c_{i} \cdot e^{d_{i} \cdot I_{i, k}}
$$

where $R_{E}$ is an integrated environmental risk; $r_{i}$ is the risk of changes in the state of the $i$ environmental medium (atmosphere, surface waters, soils); $a, b$ are estimated coefficients related to environmental medium specifics; $e$ is exponential function; $I_{i}$ is index of estimation of ecological hazard level of an impact on the $i$ environmental medium; $r_{i, k}$ is risk of changes in the state of the $i$ environmental medium by $k$ substance (individual effects assessment for each substance); $c, d$ are estimated constants, which are related to the specifics of a substance of environmental medium; $I_{i, k}$ is an index of estimation of the level of environmental hazard of $k$ substance impact on the $i$ environmental medium [3].

The coefficients associated with environmental medium specifics are obtained using the nonlinear regression method for the following environment pollutions: chemical (atmosphere, surface waters, soils); noise, infrasonic; ultrasound electromagnetic; vibration; radioactive. Levels of assessment scale for environmental hazard impact on environmental medium $(I)$ and levels of the scale of classification of the risk environmental changes $(r)$ are adopted. Assessment of the level of environmental changes risk for $i$ environmental medium is carried out in accordance with the proposed scale (Table 1) [4].

Table 1

Classification of levels of environmental changes risk

\begin{tabular}{|c|c|}
\hline Risk Level & Risk Value $R_{E}, r_{\mathrm{i}}$ \\
\hline unacceptable & $>10^{-6}$ \\
\hline conditionally acceptable & $10^{-6}-10^{-7}$ \\
\hline acceptable & $10^{-7}-10^{-8}$ \\
\hline absolutely acceptable & $<10^{-8}$ \\
\hline
\end{tabular}

On the basis of the obtained value, a decision is made on the acceptability of production complex project for each specific pollutant of the relevant environmental medium and in general [5].

The assessment methodology for technogenic safety level and industrial objects environmental impact is summarized by the principal scheme of index assessment of the hazard of potentially environmentally and technologically hazardous objects (Fig. 2). This methodology is based on the calculation of two interrelated safety indicators: the relative hazard index and the regional hazard index, which are determined on the basis of estimated aggregative indicators. Aggregative indicators characterize various aspects of enterprise safety.

The index of relative hazard of industrial enterprises is a complex indicator that takes into account:

- $\quad$ risk of technological operations execution (including storage and warehousing);

- $\quad$ possible damage from the occurrence of unplanned incidents (accidents), caused both internal and external factors; 
- $\quad$ relative hazard of enterprise location at a certain industrial site, taking into account the social and geographical features of enterprise location, which affect the possible damage as a result of emergency situations or accidents.

For a compactly located enterprise (within a single enclosed territory, regardless of its size), the resulting index of hazard is the maximum index of a number of indices that are estimated for certain types of hazards. For territorially distributed enterprises, hazard indices of their individual parts (sources of hazard) are estimated as for individual enterprises.

The risk index of hazard source functioning at an industrial plant is a combined indicator that takes into account the guaranteed lifetime of equipment operating in hazardous operations, as well as endogenous and exogenous factors that significantly affect its safety. The exogenous factor is the factor (state parameter) capable of, under the influence of natural or man-made processes, not related to the activity of the given enterprise (production cycle of this source of hazard), obtainment a value that significantly affects enterprise safety. Endogenous factors include factors (state parameters) that characterize the technological process, its equipment, and quality of service, the change of which can significantly affect industrial enterprise safety. Endogenous factors are, first of all, technological parameters of production processes, which significantly differ from the environmental parameters. Exogenous factors can be of an anthropogenic nature (transport accidents that can lead to dangerous disturbances of the normal technological process), and of spontaneous nature (earthquakes, landslides, hurricanes, and so on) [3].

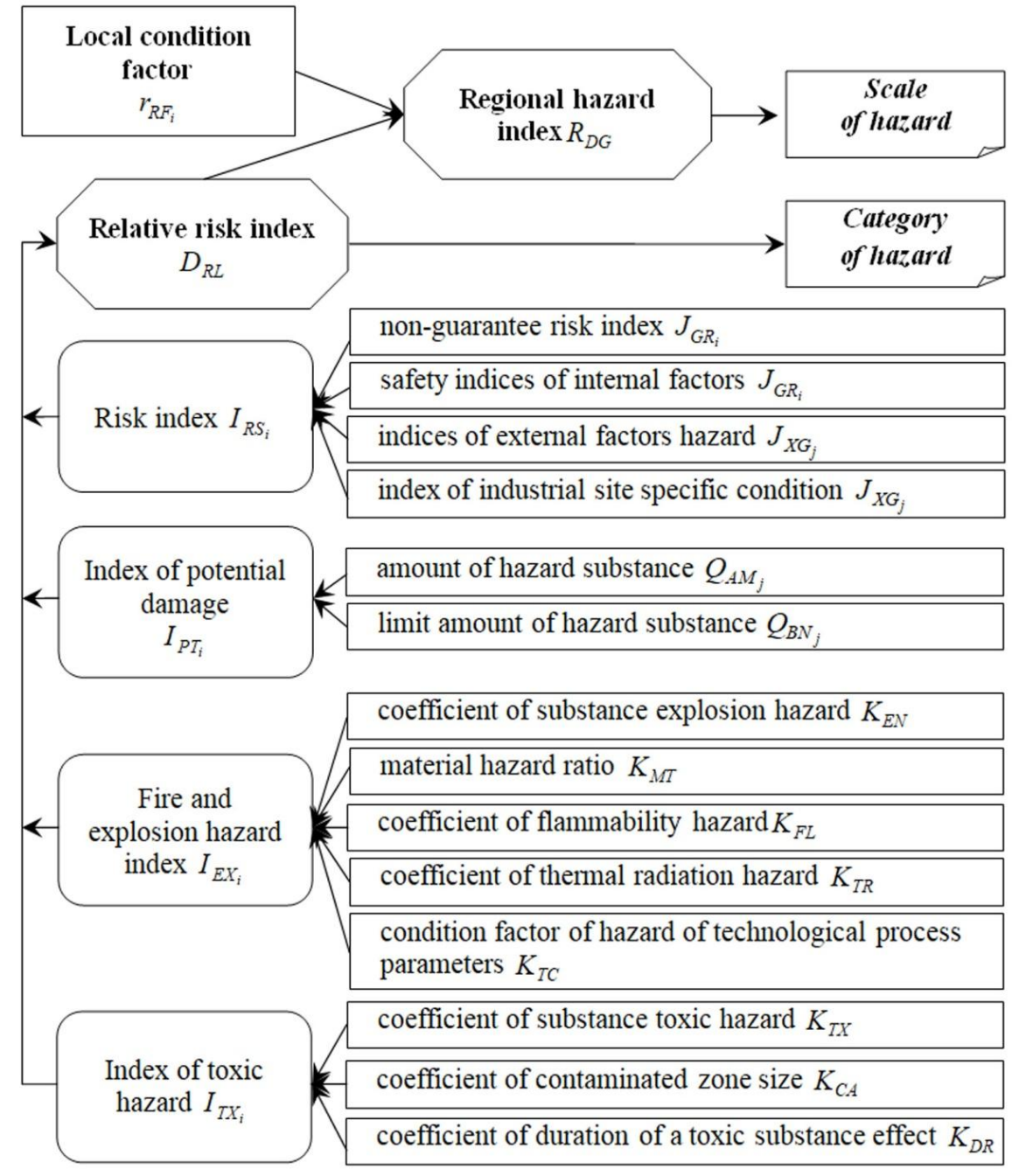

Fig. 2. Principal scheme of index estimation of the hazard of industrial enterprises. 
During the development of methodology, normative and legal documents on natural environmental protection, human health, environmental safety in Ukraine, other countries and internationally were taken into account.

It should be noted that the basis of assessment of potential damage is the limits of storage of hazardous substances (compounds) and the maximum amount of hazardous substances that may be present in the enterprise in fact. Indices of potential damage are estimated for individual sources of hazard, taking into account their possible interference.

In order to take into account the hazard of the presence of fire and explosive substances on the investigated facility, an index of fire and explosion hazard is assigned.

The presence of chemicals on an industrial site involves the obligatory account of the toxic hazard associated with the impact of chemical pollution on the environment.

The assignment of a potentially hazardous object to a certain category of hazard is carried out in accordance with the obtained values of unitary fire and explosion indices $I_{E X_{i}}$, toxic hazard $I_{T X_{i}}$, as well as risk indices $I_{R S_{i}}$ and index of potential damage $I_{P T_{i}}$, using which the unitary index of relative hazard $D_{R L_{i}}$ is estimated. Ranking of objects according to the degree of hazard is carried out on a five-level scale: up to 0.20 - safe; from 0,20 to 0,37 - low hazardous; from 0.37 to 0.63 - moderate hazard; from 0.63 to 0.80 is hazardous.

When calculating the index of relative hazard, the features of its location are not taken into account. The location of a potentially hazardous facility was considered only from the point of view of the negative impact of the environment on the safety of industrial enterprise operation. But this did not take into account the possible negative impact on the environment in the event of an accident, depending on a specific location of the object.The threat from a potentially hazardous object located in a densely populated region will be much greater than that of a similar facility located in a less populated area. The possibility of spreading harmful substances when they enter the reservoirs and rivers may also be a hazard.Dependence for the calculation of the index of relative hazard can be supplemented by new indices that are used in other methods, which provides the opportunity to comprehensively assess the level of hazard of an industrial object according to different criteria and taking into account its specificity.

The methodology for assessing the level of technogenic safety and the impact of industrial objects on the environment practically implements the system of sustainability indices under the regimen mode, or a set of indicators of the technogenic safety assessment of the enterprise and represents as Eq.2.

$$
\left\{\begin{array}{l}
D_{R L}=\max _{i=1, n}\left(D_{R L_{i}}\right) \\
D_{R L_{i}}=\exp \left\{-\frac{1}{4}\left[\begin{array}{l}
\left.\exp \left(-1,9+2,4 \cdot I_{P T i}^{\prime}\right)+\exp \left(-1,7+0,01 \cdot I_{R S i}^{\prime}\right)+\right] \\
+\exp \left(-2,1+0,01 \cdot I_{E X i}^{\prime}\right)+\exp \left(-1,9+0,01 \cdot I_{T X i}^{\prime}\right)
\end{array}\right]\right. \\
I_{R S_{i}}^{\prime}=\frac{\sum_{G R_{i}}^{n} /\left(1-J_{S P_{i}}\right)}{\prod_{E N}^{m_{E N}} J_{E N_{j}} \cdot\left[\sum_{j=1}^{m_{X G}}\left(1-J_{X G_{j}}\right)\right] / m_{X G}^{2}}, I_{P T_{i}}^{\prime}=\frac{Q_{j=1}}{n} \\
I_{E X_{i}}^{\prime}=K_{E N} \cdot K_{M T} \cdot K_{F L} \cdot K_{T R} \cdot K_{T C}, I_{T X_{i}}^{\prime}=K_{T X} \cdot K_{C A} \cdot K_{D R} \cdot K_{T C}
\end{array}\right.
$$


where $D_{R L}$ is index of relative hazard of compactly located industrial enterprise; $D_{R L_{i}}$ is index of relative hazard of a separate source; $n$ is number of sources of hazard of an industrial enterprise; $I_{R S_{i}}^{\prime}$ is index of risk of the $i$ source of hazard, taking into account the guaranteed lifetime of the equipment, endogenous and exogenous factors; $I_{P T_{i}}^{\prime}$ is index of potential damage of $i$ source of hazard and is determined by the limits of standard and maximum quantities of hazardous substances (compounds); $I_{E X_{i}}^{\prime}$ is the fire and explosion hazard index of the $i$ source of hazard takes into account the hazard from the presence of fire and explosive substances; ${ }^{\prime}{ }_{T X_{i}}$ is the toxic hazard index of the $i$ source of hazard takes into account the toxic hazard of the substance under the influence of technological parameters of the process, the duration of its impressive action and the size of the possible zone of contamination [6].

Index of regional hazard is calculated by the expression:

$$
R_{D G}=D_{R L} \cdot \sum_{i=1}^{l} r_{R F_{i}}
$$

where $r_{R F_{i}}$ is the coefficient of taking into account local characteristics; $l$ is the number of regional factors taken into account.

The coefficients of taking into account local features include:

- the condition factor of the population exposed to the risk of a hazardous object;

- the condition factor of the value of the environment (protected or resort area);

- the condition factor of the possibility of the transboundary impact of a hazardous enterprise (taking into account the distance to the border with other states);

- the condition factor of the possibility of distributing accidental discharges of hazardous substances in the aquatic environment; it is determined by the affiliation of the industrial site sources of hazard to one or another water basin (regardless of the proximity of the coastline and mandatory for all industrial enterprises).

\section{Results of hazard and risk assessment}

The regional hazard index is a comprehensive estimate and determines the expediency of placing a potentially hazardous object on the selected industrial site in connection with the possible consequences (economic, environmental, social, etc.) of accidents at industrial enterprises. The classification of industrial enterprises according to this indicator takes place in accordance with the nature of the enterprise's hazard: less 1 - local; from 1 to 10 - regional; more than 10 - state.

Thus, the use of indices enables assessing the hazard of industrial production without the development of emergency scenarios and monitoring the work conditions and equipment failures, as well as the search for analogs.

To obtain values in probabilistic estimates (technogenic risk) it is enough to use their connection with the function of desirability by the expression:

$$
\text { risk }=a \cdot e^{b \cdot d}(4)
$$

where $e$ is exponent and determined coefficients are $a=4,99 \cdot 10^{-6}$ and $b=-7,557$.

As shown, partial desirability functions have the following form:

$$
d_{P T}=\exp \left[-\exp \left(-1,994+2,470 \cdot I_{P T}^{\prime}\right)\right]
$$




$$
\begin{aligned}
d_{R S} & =\exp \left[-\exp \left(-1,720+0,0110 \cdot I_{R S}^{\prime}\right)\right](6) \\
d_{E X} & =\exp \left[-\exp \left(-2,159+0,0132 \cdot I_{E X}^{\prime}\right)\right](7) \\
d_{T X} & =\exp \left[-\exp \left(-2,159+0,0132 \cdot I_{T X}^{\prime}\right)\right]
\end{aligned}
$$

The application of this approach characterizes obtained estimates of the hazard of a gas pipeline (for example) and summarized data are presented in Table. 2. The risk due to explosive hazard is at the limit of acceptable value with other optimistic indicators. Therefore, this area is subject to constant control over the provision of production conditions [6].

\begin{tabular}{|c|c|c|c|}
\hline \multicolumn{2}{|c|}{ Indicators of risk based on index estimates } & \multicolumn{2}{|c|}{ Indicators of risk based on probabilistic estimates } \\
\hline Name of the indicator & Value & A substantial component of risk & Value \\
\hline Index of an accident & 0,19 & $\begin{array}{l}\text { the occurrence of an accident due } \\
\text { to exogenous and endogenous } \\
\text { factors, outdated equipment, etc. }\end{array}$ & $1,096 \cdot 10^{-8}$ \\
\hline $\begin{array}{c}\text { Index of Potential } \\
\text { Damage }\end{array}$ & 0,13 & $\begin{array}{l}\text { the occurrence of an accident } \\
\text { from the maximum total amount } \\
\text { of a hazardous substance of the } \\
\text { same type, its threshold mass and } \\
\text { the amount of such substances }\end{array}$ & $7,069 \cdot 10^{-9}$ \\
\hline $\begin{array}{l}\text { Index of fire and } \\
\text { explosion hazard }\end{array}$ & 0,89 & $\begin{array}{l}\text { accident due to explosive } \\
\text { substances, their quantity, the } \\
\text { hazard of flare, thermal radiation }\end{array}$ & $2,191 \cdot 10^{-6}$ \\
\hline Relative Risk Index & 0,09 & $\begin{array}{l}\text { possible negative consequences in } \\
\text { the event of an accident at the } \\
\text { enterprise, taking into account the } \\
\text { worst case scenario }\end{array}$ & $4,937 \cdot 10^{-9}$ \\
\hline Regional Hazard Index & 0,17 & $\begin{array}{l}\text { possible emergency situations due } \\
\text { to features of the location of the } \\
\text { facility (proximity to oil pipelines, } \\
\text { railways, etc.). }\end{array}$ & $9,071 \cdot 10^{-9}$ \\
\hline Hazard category - lc & facility & \multirow{2}{*}{\multicolumn{2}{|c|}{ The risk level is acceptable }} \\
\hline The scale of hazard - & oriented & & \\
\hline
\end{tabular}

Table 2

Results of assessment of hazard and risk

It should be noted that the system of indices is a measure of the criticality of an object stable mode. If the indices of regular work change, then the index values also change accordingly, and thus a probabilistic risk assessment.

While determining the indices for conditions of stable work we obtain the magnitude of the predicted level of risk, and for critical values of parameters - the value of the risk of the accident.

The developed methods have a modern program implementation.

Improvement of the regional development policy requires the involvement of long-term forecasting, ecological, economic, and sociological planning and strategic environmental assessment for the territorial planning system. Implementation of strategic environmental assessment in the planning process involves joint efforts to collect and analyze data, engage stakeholders and the public in order to effectively make decisions. Such joint activity is 
impossible without the continuous interaction of management, expert and interested parties, and therefore interaction should be built on the basis of a decision-oriented model.

Since the security of the regions is an integral part of sustainable development, the developed methodology is the basis for the development of implementation tools of strategic environmental assessment. For example, as a development indicator, an indicator of anthropogenic hazard is used $I_{T D}=\bar{\rho}_{R} \cdot J_{T D_{\Sigma}}, \bar{\rho}_{R}$ is the relative density of population in the region, $J_{T D_{\Sigma}}$ is a generalized index of the technogenic hazard of the region, $J_{T D_{\Sigma}}=\sum_{i=1}^{n} J_{T D_{i}}$. The use of technogenic safety indicator will give a more complete picture of the sustainability level of individual territories and will provide an opportunity to see the actual level of man-made load.

\section{Conclusion}

This approach can be applied not only to existing industrial enterprises but also at the design stage in case of conducting a strategic environmental assessment or environmental impact assessment.The development of tools for implementing functions of strategic environmental assessment reduces uncertainty, increases the efficiency and adaptability of the decision-making cycle, facilitates access to information by experts, stakeholders and the public when conducting an environmental assessment of projects. The solution of these tasks contributes to the improvement of environmental legislation in the application of strategic environmental assessment as a compulsory instrument for strategic planning of socio-economic policy development at the national, regional and local levels, improvement of environmental protection, harmonization of economic, social and environmental development goals in regional strategies, plans, and programs.

\section{References}

[1] T. V. Boyko, I. M. Dzhygyrey, "An analysis of planning objects for strategic environmental assessment based on indicator approach," Mizhnar. nauk.-prakt. konf. Komp'yuterne modelyuvannya $v$ himiyi i tehnologiyah ta sistemah stalogo rozvitku, 2016, pp. 219-225.

[2] A. O. Abramova, "Perspektivni napryamki rozvitku protseduri otsinki vpliviv na navkolishne seredovishche," Naukova Ukrayina, 2016. [Online]. Available: http://globalnauka.com/naukova_ukraina/1490.html. [Accessed April 10, 2018].

[3] T. V. Boyko, A. O. Abramova, "System analysis of interaction of man-made object of industrial and environmental," Mizhnar. nauk.-prakt. konf. Komp'yuterne modelyuvannya $v$ himiyi i tehnologiyah ta sistemah stalogo rozvitku, 2016, pp. 226-231.

[4] T. Boyko, A. Abramova, "Definition of environmental risk as integral criterion in assessing of man-caused load," Eastern-European Journal of Enterprise Technologies, Vol. 3, Issue 10 (69), 2014, pp. 4-7.

[5] A. Abramova, "Index estimation of environmental safety for designing industrial facilities," Technology audit and production reserves, Vol. 6, Issue 1 (8), 2012, pp. 39-40.

[6] G. Statyukha, T. Bojko, V. Bendyug, "For the question of technogenious hazard estimation of industrial objects from the position of sustainability," Summaries of $15^{\text {th }}$ International Congress of Chemical and Process Engineering “Chisa 2002”, Praha (Czech Republic), 2002, pp. 15.8 . 